\title{
Understanding Extreme Deformation with Metallography
}

L. E. Murr

Department of Metallurgical and Materials Engineering, The University of Texas at El Paso, El Paso, TX 79968

Processes like explosive welding, friction-stir welding and processing, wire drawing, ballistic and hypervelocity impact and penetration, and explosively formed or shaped-charge penetrators are all examples of extreme deformation where metals and/or alloys must flow in the solid state. In this extreme deformation regime, characterized by true strains ranging from 2 to $>6$ and strain rates ranging from $10^{3}$ to $10^{7} \mathrm{~s}^{-1}$, ordinary dislocation slip is only a fractional contributor to the deformation process. The process or processes are dominated by varying degrees of dynamic recovery and recrystallization to produce equiaxed, very fine grain structure $(\leq 1 \mu \mathrm{m})$ accommodating superplastic flow by interfacial sliding. These features are very convincingly demonstrated by a range of light and electron metallography observations [1-3]. A few examples and some related microstructural issues are presented in the accompanying figure components.

Figure 1(a) shows an optical micrograph of shock-induced deformation twins in an iron explosively formed penetrator head. Deformation twins often serve as precursors to dynamic recovery and recrystallization (DRX) phenomena and this feature is illustrated in part in Fig. 1(b) which shows deformation twins and shear bands composed of DRX grains outside of a DRX zone in the head of a $\mathrm{W}-4 \%$ Ta [001] single-crystal rod penetrator fragment in an iron target; following impact at 1.5 $\mathrm{km} / \mathrm{s}$. Figure 1(c) shows a TEM view of equiaxed, DRX grains in the center of a Ta shaped-charge slug which was soft recovered. Figure 1(d) shows a typical view of a friction-stir weld zone in aluminum 2024. A variety of precipitates within the DRX microstructure are also observed. Recent observations have also shown that non-coherent, dispersed particles such as $\mathrm{Al}_{2} \mathrm{O}_{3}$ or $\mathrm{SiC}$ are also homogeneously stirred into the weld zone by DRX-related solid-state flow [4,5]. Numerous other examples of DRX-related flow phenomena will also be presented, especially involving adiabatic shear bands.

Adiabatic shear bands are composed of two or more layers of DRX grains. These layers glide one over the other and can allow for large displacements or flow between large blocks of solid material. Thick shear bands act like fluid layers which can transport large blocks of solid material. The movement of large dispersoids in friction-stir welding is a particularly striking example observed by optical metallography [6].

\section{References}

[1] L. E Murr et al., Mater. Res. Innovations 1 (1998) 211.

[2] L. E. Murr et al., J. Mater. Sci. 37 (2002) 3337.

[3] E. A. Trillo et al., Mater. Character. 48 (5) (2002) 407.

[4] D. J. Shindo et al., J. Mater. Sci. 37 (23) (2002) 4999.

[5] R. A. Prado et al., Mater. Sci. Engng. A (2002) .

[6] Research supported by a Mr. and Mrs. MacIntosh Murchison Endowed Chair at the University of Texas at El Paso. 



FIG. 1. Examples of metallographic observations involving extreme deformation. (a) Deformation twins in an iron explosively formed penetrator. (b) Twins, shear bands, and DRX zone in a W- $4 \%$ Ta single-crystal penetrator fragment in an iron target. (c) DRX zone in a Ta shaped-charge slug center. (d) DRX grains in the center of an aluminum 2024 friction-stir weld zone. 